\title{
Transisi Keadaan Defect-Non Defect pada Konveksi Listrik Kristal Cair Nematic Homeotropic dibawah Pengaruh Medan Magnet
}

\author{
Fahrudin Nugroho, Yoshiki Hidaka, Tatsuhiro Ueki, Shoichi Kai \\ Jurusan Fisika, Fakultas Mematika dan Ilmu Pengetahuan Alam, Universitas Gadjah Mada, Indonesia \\ Deparment of Applied Quantum Physics and Nuclear Engineering, Faculty of Engineering, Kyushu University, Japan \\ fakhrud@ugm.ac.id
}

\begin{abstract}
Abstrak - Dalam penelitian kali ini akan dikaji fenomena konveksi listrik kristal cair nemaik homeotropik dibawah pengaruh medan magnet luar. Dalam percobaan dapat diamati fenomena munculnya defect pada soft mode turbulence yaitu spatiotemporal chaos akibat interaksi moda konveksi listrik dengan moda Nambu-Goldstone. Dapat diamati bahwa terjadi transisi keadaan defect ke keadaan non defect yang terjadi pada medan magnet kritis tertentu Hc = $450 \mathrm{G}$. Lebih lanjut dengan pengamatan cross polarizer telah berhasil dijelaskan femonena terjadinya transisi dari keadaan defect ke non defect tersebut. Hal itu diakibatkan oleh tertekannya kebebasan berotasi dari kristal cair nematik.
\end{abstract}

Kata kunci: konveksi listrik, kristal cair nematik, soft mode turbulence, moda Nambu-Goldstone, transisi keadaan

Abstract - The phenomenon of electroconvection of homeotropic nematics under influence of external magnetic field has been researched in the present study,. In the experiment, can be observed the appearance of defect in the soft-mode turbulence which is a kind of spatiotemporal chaos generated by nonlinear interaction betweenthe Nambu-Goldstone mode and the convective mode. The transition between the defect to non-defect state occurs at the critical magentic field Hc = $450 \mathrm{G}$. Furthermore, using the cross polarizer observation the mechanism of occurence of the transition can be explained. That is, it is due to the supression of the rotational freedom of nematic liquid crystal.

Key words: lectroconvection, nematic liquid crystal, soft mode turbulence, Nambu-Goldstone mode, phase transition

\section{PENDAHULUAN}

Defect yang disebabkan ketidaksempurnaan topologis telah banyak dikaji dalam banyak sistem. Salah satu contoh yang sangat popoler adalah defect pada sistem kristal yang secara mikroskopik merupakan ketidaksempurnaan dalam susunan atom- atom penyusunnya [1]. Seringkali defect dalam struktur kristal merupakan suatu hal yang di anggap tidak baik, karena berakibat kelemahan struktur zat padat. Disisi lain ada satu manfaat dari defect secara Fisika, yaitu seringkali sifat defect mencerminkan sifat sistem di mana defect tersebut diamati.

Dalam penelitian kali ini, akan disajikan hasil pengamatan defect pada konveksi listrik kristal cair nematik homeotropik. Sebagaimana diketahui bahwa sistem ini merupakan salah satu contoh sistem di luar kesetimbangan termodinamik $[2,3,4,5]$. Pada sistem kristal cair nematik homeotropik kristal cair ditempatkan diantara dua keping elektroda transparan. Orientasi kristal cair adalah tegak lurus terhadap elektroda sehingga terdapat simetri rotasi yang kontinyu pada bidang elektroda (bidang $\mathrm{x}-\mathrm{y}$ ). Dengan menerapkan arus listrik bolak-balik (AC) dengan tegangan di atas ambang batas Freedericksz VF orientasi rerata dari kristal cair nematik $\mathrm{n}$ mengalami kemiringan terhadap sumbu z yang disebabkan adanya sifat anisotropik dielektrik pada kristal cair yang digunakan. Karenanya terjadi pemecahan simetri rotasi yang kontinyu (Symmetry Breaking). Proyeksi $\mathrm{n}$ pada sumbu $\mathrm{z}$ yang disebut $\mathrm{C}(\mathrm{r})$, dimana $\mathrm{r}$ adalah vektor posisi dua dimensi pada bidang $\mathrm{x}-\mathrm{y}$, bebas berotasi pada bidang $\mathrm{x}-\mathrm{y}$ dan bersifat sebagai moda Nambu-Goldstone. Dengan menerapkan tegangan yang lebih besar, yaitu di atas ambang batas konveksi listrik Vc, maka konveksi listrik terjadi pada sistem dikarenakan ketakstabilan Carr-Helfrich [5]. Konveksi listrik dengan vektor gelombang $\mathrm{q}(\mathrm{r})$ berinteraksi secara tak linear dengan C(r) menghasilkan formasi pola tak teratur yang disebut dengan soft-mode turbulence (SMT).

Penelitian defect pada SMT, yang kemudian diberi nama blacklines, sudah dilakukan oleh beberapa peniliti sebelumnya [1, 3, 6]. Dalam penelitian tersebut diteliti terkait dengan sifat dasar dari defect tersebut. Dalam artikel ini akan dikaji secara eksperimental sifat blacklines yang dipengaruhi oleh medan magnet luar $\mathrm{H}$. Akan ditunjukan pula terjadinya transisi keadaan Defect ke Non-Defect pada tingkat edan magnet tertentu. Akhirnya akan ditunjukan bahwa terdapat kaitan yang erat antara transisi Defect ke Non-Defect dengan transisi keadaan Chaotic ke keadaan Teratur dalam sistem ini.

\section{EKSPERIMEN}

Untuk menjelaskan sifat-sifat transisi seperti yang telah disebutkan di atas telah kami lakukan percobaan dengan menggunakan kristal cair nematik p-methoxy-benzilidenp'-n-buthyl-annyline (MBBA) yang di injeksikan di antara dua elektroda transparan indium tin oxide (ITO) dengan diameter $12.9 \mathrm{~mm}$ dengan jarak $\mathrm{d}=52 \pm 1 \mu \mathrm{m}$. Rancangan dari percobaan yang telah kami lakukan pada dasarnya 
serupa dengan percobaan yang telah sebelumnya [7]. Semua pengukuran dilakukan pada suhu stabil $30.00 \pm 0.05^{\circ} \mathrm{C}$. Konstanta dielekrtik $\varepsilon \|$ dan konduktifitas listrik $\sigma \|$ dari sampel adalah masing-masing $6.4 \pm 0.1$ and $8.7 \pm 0.1 \times$ $10-7 \Omega-1 \mathrm{~m}-1$. Medan magnet konstan $\mathrm{H}$ di kenakan pada sampel secara kolateral (sejajar elektroda) dihasilkan dari piranti elektromagnet (TAMAGAWA GP060-60R), besarnya medan magnet ini diukur dengan Gauss meter (Yokogawa 3251). Sebuah Charged Coupled Device (CCD) kamera (Sony XCL 5005) yang digunakan bersamaan dengan Mikroskop dan software (DPX-CLM 100 basic) digunakan untuk mengamati dan menangkap citra SMT pada bidang $\mathrm{x}-\mathrm{y}$. Ukuran dari citra yang ditangkap dalam bentuk data adalah $1.14 \mathrm{~mm} \times 1.14 \mathrm{~mm}(1000$ pixel $\times 1000$ pixel).

Berikut ini adalah langkah-langkah percobaan yang telah dilakukan untuk memperoleh data. Pertama-tama, untuk menghindari pengaruh perubahan frekuensi f tegangan $\mathrm{AC}$ yang digunakan kami gunakan frekuensi ternormalkan $\eta \equiv$ $[\mathrm{f}-\mathrm{fL}(\mathrm{H})] / \mathrm{fL}(\mathrm{H})=-0.5$ dimana $\mathrm{fL}(\mathrm{H})$ adalah perubahan frekuensi Lifshitz akibat perubahan medan magnet luar [8]. Dengan demikian pola yang selalu diamati pada percobaan kali ini selalu merupakan pola oblique rolls (OR) [7, 8]. Selanjutnya kami terapkan medan magnet luar dibawah medan magnet ambang Fr' eedericksz HF selama satu menit. Kemudaian tegangan $\mathrm{V}$ diterapkan di atas VF selama 10 menit sampai keadaan homogen $\mathrm{C}(\mathrm{r})$ bisa tercapai. Kemudian tegangan listrik tersebut dinaikan di atas ambang batas konveksi sampai diperoleh parameter kendali (control parameter) $\varepsilon \equiv(\mathrm{V} / \mathrm{Vc}) 2-1$ dengan magnitudo yang diharapkan. Proses ini dilakukan sampai keadaan transient terlampaui. Citra dari pembentukan pola-pola pada sistem ini kemudian diambil dengan selang waktu 2 menit. Analisa citra pola kemudian dilakukan dengan ImageJ dan software dalam bahasa $\mathrm{C}$.

\section{HASIL DAN PEMBAHASAN}

Setelah dilakukan percobaan maka dapat diperoleh data citra seperti ditunjukan oleh Gambar 1. Dari Gambar 1 tampak bahwa dengan mengenakan medan magnet luar $\mathrm{H}$ yang lebih kuat maka jumlah dan panjang defect yang berupa blacklines semakin berkurang. Gambar 1 (c) dan (d) menunjukan bahwa pada akhirnya blacklines akan hilang dengan menerapkan besar medan magnet luar tertentu. Selain itu dapat diamati pula bahwa seiring dengan berkurangnya jumlah dan panjang blacklines maka citra dari pola SMT semakin teratur. Karenanya kami menduga ada kaitan yang erat antara keadaan SMT dengan jumlah dan panjang blacklines yang teramati padanya.

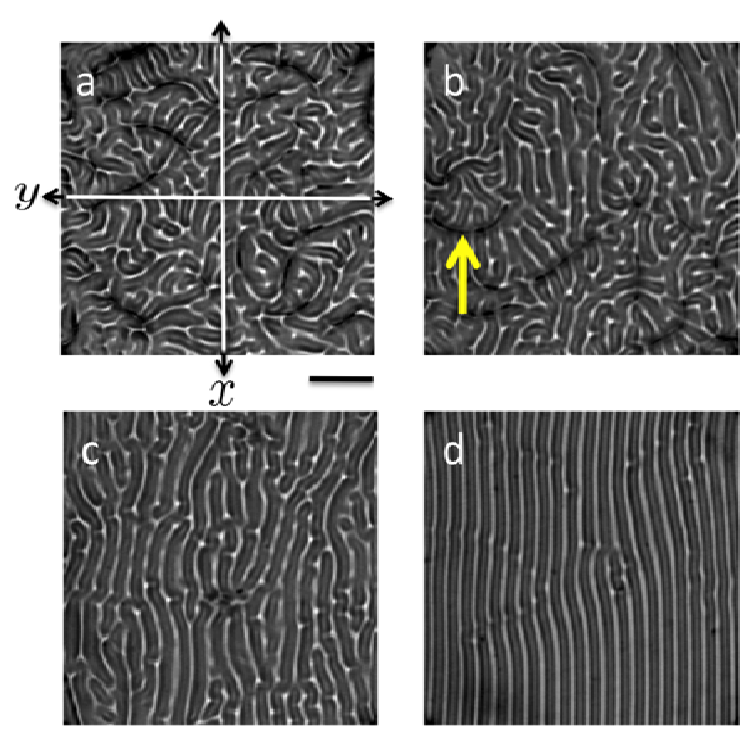

Gambar 1. Berkurangnya jumlah dan panjang blacklines seiring dengan bertambahnya besar medan magnet luar yang diterapkan pada SMT. (a) $\mathrm{H}=50[\mathrm{G}]$, (b) $\mathrm{H}=350[\mathrm{G}]$, (c) $\mathrm{H}=450[\mathrm{G}]$ and (d) $\mathrm{H}=650[\mathrm{G}]$ dengan $\varepsilon=0.1$. Tanda panah pada (b) menunjukan salah satu blacklines.

Untuk dapat menjelaskan kaitan antara kedaan SMT dan keadaan teratur dengan transisi keadaan defect dan non defect secara kuantitatif, kami telah mengukur rapat blacklines $\rho_{\mathrm{BL}}$ yaitu panjang blacklines dibagi dengan luas citra yang diobservasi yang ditunjukan oleh Gambar 2 .

Gambar 2 menunjukan hubungan $\rho_{\mathrm{BL}}$ dengan besar medan magnet luar H. Dari gambar tersebut tampak bahwa terdapat suatu medan magnet tertentu dimana blacklines benar-benar akan hilang. Dari data gambar 2 telah kami coba untuk mencocokan (fitting) fungsi dari $\rho_{\mathrm{BL}}$ sebagai fungsi $\mathrm{H}$ dengan menggunakan metode kuadrat terkecil (least square). Salah satu hasil yang paling mendekati pecocokan fungsi tersebut ditunjukan dengan garis merah pada gambar 2. Dari gambar tersebut dapat di simpulkan bahwa besarnya Hc dimana blacklines akan hilang $\left(\rho_{\mathrm{BL}}=0\right)$ adalah sebesar $\mathrm{H}=450 \pm 2$ G. Karenanya kami memperkirakan bahwa selain terjadinya transisi antara keadaan defect dengan non defect maka pada nilai ini juga terjadi transisi dari keadaan SMT ke keadaan teratur. 


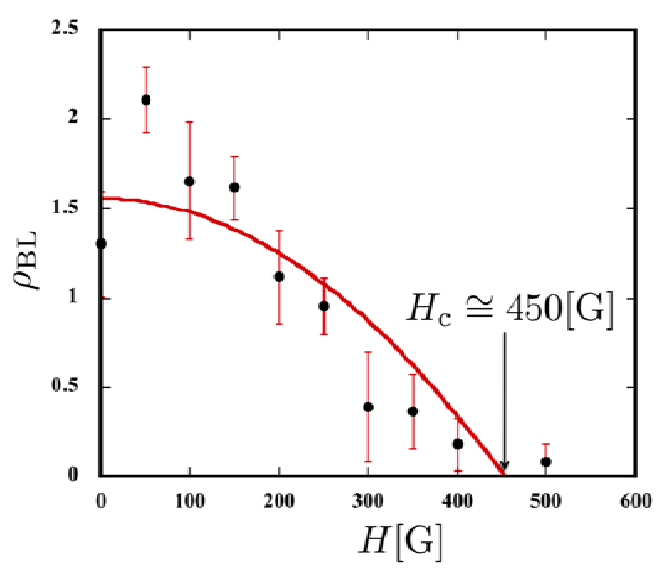

Gambar 2. Rapat blacklines $\rho_{\mathrm{BL}}$ versus besar medan magnet luar $\mathrm{H}$ pada parameter control tetap $\varepsilon=0.1$.

Gambar 2 menunjukan hubungan $\rho_{\mathrm{BL}}$ dengan besar medan magnet luar H. Dari gambar tersebut nampak bahwa terdapat suatu medan magnet tertentu dimana blacklines benar-benar akan hilang. Dari data gambar 2 telah kami coba untuk mencocokan (fitting) fungsi dari $\rho_{\mathrm{BL}}$ sebagai fungsi $\mathrm{H}$ dengan menggunakan metode kuadrat terkecil (least square). Salah satu hasil yang paling mendekati pecocokan fungsi tersebut ditunjukan dengan garis merah pada gambar 2. Dari gambar tersebut dapat di simpulkan bahwa besarnya Hc dimana blacklines akan hilang $\left(\rho_{\mathrm{BL}}=0\right)$ adalah sebesar $\mathrm{H}=450 \pm 2$ G. Karenanya kami memperkirakan bahwa selain terjadinya transisi antara keadaan defect dengan non defect maka pada nilai ini juga terjadi transisi dari keadaan SMT ke keadaan teratur.

Untuk sementara kaitan antara kedua transisi keadaan ini masih bersifat fenomenologis. Artinya belum bisa dibuktikan secara teoretis hubungan antara keduanya. Untuk itu diperlukan kajian teoretis lebih lanjut dan tidak akan dibahas dalam kesempatan kali ini. Suatu kajian teoretis melalui persamaan Rossberg [9] sedang dilakukan dan akan dipublikasikan pada kesempatan berikutnya[10].

Selanjutnya untuk menjelaskan fenomena transisi keadaan defect ke Non-defect kami melakukan percobaan menggunakan cross polarizer. Dari penelitian sebelumnya telah diketahui bahwa blacklines merupakan defect berupa garis dengan titik defect yang menyertainya. Karenanya kali ini percobaan difokuskan untuk mengetahui pengaruh medan magnet terhadap titik defect tersebut. Pengamatan ini dilakukan untuk mengetahui struktur mikroskopik yaitu C(r) disekitar titik defect. Hasil dari pengamatan tersebut dapat dilihat pada Gambar 4 sebagai berikut. (a)

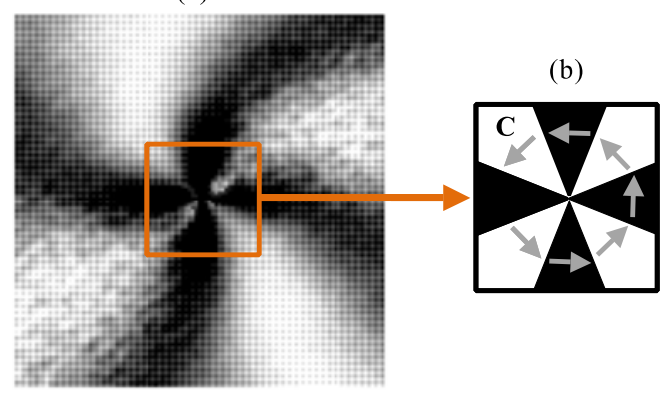

Gambar 4. Salah satu titik defect di bawah observasi dengan cross polarizer (cross-Nicol observation) (a). Skema formasi C(r) disekitar titik defect ditunjukan pada (b).

Dari gambar 4 di atas dapat dilihat bahwa titik defect merupakan formasi khusus (melingkar) dari C(r). Formasi semacam itu hanya bisa terjadi jika dan hanya jika $\mathrm{C}(\mathrm{r})$ bebas berotasi terhadap sumbu z. Dari pengamatan ini dapat diperoleh suatu fakta penting yang menjelaskan terjadinya pengurangan jumlah dan panjang blacklines akibat adanya pengarauh medan magnet luar. Yaitu dengan mengingat sifat diamagnetik bahan kristal cair yang di gunakan (MBBA), maka dengan mengenakan medan magnet luar maka molekul MBBA akan berusaha berorientasi sejajar dengan medan magnet luar. Sebagai konsekuensinya kebebasan $\mathrm{C}(\mathrm{r})$, yang merupakan proyeksi n pada bidang $\mathrm{x}$ $y$, untuk berotasi akan berkurang. Semakin besar medan medan magnet luar dikenakan pada sistem, maka kebebasan C(r) untuk berotasi akan semakin besar. Peluang untuk terjadinya formasi $\mathrm{C}(\mathrm{r})$ yang melingkar, seperti ditunjukan oleh gambar 4, agar terbentuk satu titik defect yang merupakan pembentuk blacklines semakin kecil. Pada besar medan magnet tertentu yang cukup besar maka baik $n$ maupub C(r) akan berorientasi sejajar $\mathrm{H}$, sebagai akibatnya defect tidak mungkin lagi terjadi, defect akan hilang dan $\rho_{\mathrm{BL}}(\mathrm{H}=\mathrm{Hc})=0$.

\section{KESIMPULAN}

Setelah melakukan serangkaian percobaan terhadap SMT dibawah pengaruh medan magnet luar dan serangkaian analisa dapat diperoleh kesimpulan sebagai berikut. (i) Dengan mengenakan medan magnet luar maka akan terjadi transisi keadaan defect ke keadaan non defect pada SMT. (ii) Telah ditunjukan bahwa struktur makroskopik defect merupakan konsekuensi dari struktur mikroskopik dari sistem, yaitu defect hanya bisa terjadi jika formasi dari C(r) adalah bersifat khusus, misalnya melingkar. (iii) Transisi dari keadaan defect ke non defect ini diperkirakan terkait dengan transisi keadaan chaotic ke keadaan teratur. Perlu penelitian teoretik terhadap fenomena transisi tersebut. 


\section{UCAPAN TERIMA KASIH}

Terakhir salah satu penulis (F.N.) mengucapkan terimakasih atas dukungan dari Core to Core Program "International research network for non-equilibrium dynamics of soft matter." F. N. Juga berterimakasih atas dukungan dari DIKTI dan DIKNAS.

\section{PUSTAKA}

\section{Artikel jurnal:}

[1] R. Anugraha, T. Ueki, Y. Hidaka, N. Oikawa, and S. Kai: Phys. Rev. E. 100 (2009) 164503.

[2] S. Kai, K. Hayashi, and Y. Hidaka, J. Phys. Chem. 100, 19007 (1996). Y. Hidaka, K. Tamura, and S. Kai: Prog. Theor. Phys. Suppl. 161 (2006) 1.

[3] R. Anugraha, F. Nugroho, T. Ueki, Y. Hidaka, and S. Kai: Phys. Rev. E. 83 (2011) 022701.

[4] H. Richter, N. Klöpper, A. Hertrich, A'. Buka: Europhys. Lett. 30 (1995) 37.
[5] M. Tribelsky and K. Tsuboi: Phys. Rev. Lett. 76 (1996) 1631 A. Hertrich, W. Decker, W. Pesch, and L. Kramer: J. Phys. II (France) 2 (1992) 1915.

[6] J.-H. Huh, Y. Hidaka, and S. Kai: J. Phys. Soc. Jpn. 68 (1999) 1567.8

[7] E. Bodenschatz, W. Zimmermann, and L. Kramer, J. Phys. (Paris) 49, 1875 (1988).

[8] F. Nugroho, T. Ueki, R. Anugraha, Y. Hidaka, and S. Kai: J. Phys. Soc. Jpn. 79 (2010) 2.

[9] A. G. Rossberg:. A. G. Rossberg, A. Hertrich, L. Kramer, and W. Pesch: Phys. Rev. Lett. 76 (2002) 4729. A. G. Rossberg, and L. Kramer: Phys. Scr. T. 67 (1996) 121. A. G. Rossberg, A. Hertrich, L. Kramer, and W. Pesch: Phys. Rev. Lett. 76 (2002) 4729.

[10] A. G. Rossberg, komunikasi pribadi.

\section{Skripsi/tesis/disertasi:}

[11] A. G. Rossberg, The Amplitude Formalism for PatternForming Systems with Spontaneously Broken Isotropy and some Applications, Ph.D. dissertation, University of Bayreuth, 1998. 